\title{
REABILITAÇÃO ESTÉTICA DE PACIENTE PORTADOR DE DISPLASIA DO ECTODERMA - RELATO DE CASO CLÍNICO
}

\author{
ESTHETIC REHABILITATION OF A PATIENT WITH ANHYDROTIC \\ ECTODERMAL DYSPLASIA - A CASE REPORT
}

\author{
Márcia Cançado Figueiredo ${ }^{1 *}$, Cinthya Aline d. Guarienti², \\ Vanessa Constant Barreto ${ }^{2}$, Régia Soraggi ${ }^{1}$ \\ 1* Autor para contato: Universidade do Rio Grande do Sul - UFRGS, Faculdade de \\ Odontologia, Porto Alegre, RS, Brasil; (51) 3308-5026; e-mail: marciacf@myway.com.br \\ 2 Universidade do Rio Grande do Sul - UFRGS, Programa de Pós-graduação em Odontologia, \\ Porto Alegre, RS
}

Recebido para publicação em 12/03/2007

Aceito para publicação em 13/08/2007

\section{RESUMO}

O presente relato de caso clínico descreve a reabilitação oral e o acompanhamento odontológico de um paciente infantil, afetado pela displasia do ectoderma do tipo anidrótica, utilizando-se da odontologia estética adesiva, durante quatro anos. O paciente iniciou o tratamento aos três anos de idade, sendo que foram confeccionadas próteses parciais removíveis, com o intuito de reabilitar a função dos dentes decíduos não formados, bem como restaurações estéticas em resina composta nos dentes presentes com formato conóide. Com o crescimento e desenvolvimento facial do paciente e com a erupção dos dentes permanentes, foi necessária a confecção de novas próteses removíveis, assim como restaurações estéticas nos dentes permanentes. O tratamento escolhido (protético/restaurador) proporcionou melhora na função e estética bucal, proporcionando bem estar psicológico ao paciente, que permanecerá em acompanhamento até o seu completo crescimento e desenvolvimento oral.

Palavras-chave: displasia ectodérmica; estética; reabilitação bucal

\begin{abstract}
The present case report describes the oral rehabilitation and the odontological follow-up of a child affected by anhydrotic ectodermal dysplasia by means of esthetic restorative dentistry, a procedure that lasted four years. The patient began the treatment at age three, when partial removable prostheses were made with
\end{abstract}


the aim to replace the missing teeth, while esthetic restorations with composite resin materials were used in the conical-shaped primary teeth present. With the growing and development of the patient's face and the eruption of permanent teeth, it was necessary to replace the partial removable prostheses and to perform esthetic restorations on the permanent teeth. The treatment chosen (prosthodontic and restorative) improved the esthetic and oral functions and provided psychological and social comfort to the child, who will remain under odontological treatment until it is completely grown-up and orally developed.

Key words: ectodermal dysplasia, esthetics, oral rehabilitation

\section{Introdução}

As displasias ectodérmicas são síndromes, descritas primeiramente por Widdenburn em 1929(Gardel P., Mercier C., Molhant G.), como um grupo de doenças hereditárias caracterizadas por defeitos no desenvolvimento de um ou mais tecidos de origem ectodérmica. Segundo Corrêa et al. (1997) e Oliveira et al. (2000), podem manifestar-se sob duas formas: hidrótica (síndrome de Fischer-Jacobsen-Clouston) e hipohidrótica ou anidrótica (síndrome de Chris-SiemesTouraine). A forma mais freqüente é a síndrome de Chris-Siemes-Touraine e sua freqüência estimada na população é cerca de um para cada 100.000 nascimentos, tendo uma prevalência maior em homens do que em mulheres, já que o distúrbio possui na sua maioria caráter recessivo ligado ao sexo (cromossomo $\mathrm{X}$ ), embora algumas formas possam ser transmitidas como caráter autossômico dominante (hidrótica). Nos casos raros de dominância do gene, os sinais clínicos da displasia são menos severos (Bartstra et al.; Bergendal, B.; Daniel et al.; Motil et al.; Toledo et al.). As características mais observáveis na displasia do tipo anidrótico são: hipotricose (cabelos, sobrancelhas, cílios e pêlos escassos), hipohidrose (escassez de fluídos: lágrimas, saliva, suor), hipodontia ou anodontia, alterações nas glândulas mucosas e sebáceas e diminuição ou mesmo ausência de glândulas sudoríparas, comumente associadas à hipertermias recorrentes $\mathrm{e}$ incapacidade de suportar altas temperaturas (Bartstra et al.; Corrêa et al.; Oliveira et al.) Os indivíduos portadores desta síndrome possuem a pele geralmente lisa, fina e seca, unhas atróficas ou quebradiças, palmas das mãos e pés com queratoses, apresentando aparência senil. Na forma hidrótica, em grande parte dos casos, a hipodontia é o único achado relacionado à presença do distúrbio. Além destas características, os indivíduos portadores desta síndrome podem apresentar lábios protuberantes e evertidos, depressão da ponte nasal, orelhas proeminentes e, algumas vezes pigmentação ao redor dos olhos (Bartstra et al.; Bergendal B.; Oliveira et al.; Motil et al.). As características bucais da displasia do tipo anidrótica são: hipodontia, anodontia parcial ou total (rara), crista alveolar estreita (forma de lâmina de faca), erupção dental tardia, dentes anteriores conóides, dentes posteriores com formas atípicas, com cúspides mais proeminentes, processo alveolar atrofiado, diminuição da dimensão vertical, queilite angular crônica, hipoplasia das glândulas salivares menores do lábio, mucosa e faringe (Corrêa et al.; Oliveira et al.; Bartstra et al.; Muzio et al.; Toledo et al.) As características da displasia do tipo hidrótico, em geral são semelhantes à do tipo anidrótico, porém são menos severas.

A etiologia desta síndrome é desconhecida, porém, alguns estudos genéticos demonstram que a displasia do ectoderma está relacionada com a mutação do gene EDA(Ectodermical Displasics Anidrotic). Este gene localiza-se na posição q12-q13 do cromossomo X e possui uma proteína transmembrana de 135 aminoácidos que são expressos em queratinócitos, folículos capilares e glândulas sudoríparas. Provavelmente aparece no primeiro trimestre de gestação. Se for uma forma severa, há probabilidade de ter ocorrido antes da $6^{\circ}$ semana, afetando a dentição. Se ocorrer após a $8^{\circ}$ semana de VIU outras estruturas ectodérmicas serão afetadas (Hertz et al.; Kobielak et al.; Motil et al.; Muzio et al.) 
Do ponto de vista odontológico, os pacientes portadores da síndrome formam um grupo de pacientes especiais que, desde cedo, requerem acompanhamento por equipe multidisciplinar, sendo que o prognóstico é influenciado pelos padrões e sinais clínicos apresentado, bem como pela idade do paciente. Pode-se devolver o equilíbrio funcional e estético diante das condições bucais apresentadas pela síndrome através da ação conjunta entre as várias áreas da Odontologia, visando o bem-estar físico e emocional do paciente, já que na maioria dos casos clínicos relatados pela literatura, a principal queixa dos pacientes é quanto à aparência (Novais, Abud.; Oliveira et al.).

Toledo et al. sugerem uma reabilitação com próteses parciais removíveis e corrobora com Bergendal B., no que diz respeito à necessidade de troca dessas próteses quando o paciente atingir a idade de 6 a 7 anos, para não provocar restrição no crescimento esquelético e da articulação têmporo-mandibular. Os autores propõem como solução a colocação de implantes em crianças de 8 anos de idade para melhor fixação de uma overdenture.

Sendo assim, o objetivo do presente estudo é relatar o acompanhamento de um caso de displasia ectodérmica anidrótica durante quatro anos, bem como descrever o tratamento odontológico oferecido a este paciente.

\section{Relato do caso}

Paciente L.G. I., sexo masculino, 3 anos de idade, apresentou-se à Bebê Clínica da Faculdade de Odontologia da Universidade Federal do Rio Grande do Sul, procurando por atendimento odontológico. A principal queixa relatada pela mãe era a aparência do filho, além da dificuldade que o mesmo possuía em alimentar-se, pela ausência de vários dentes. Na anamnese e exame clínico, observou-se que a criança possuía sinais clínicos que condiziam com o diagnóstico de displasia ectodérmica anidrótica. A mãe desconhecia até então esta síndrome, e foi encaminhada ao Hospital de Clínicas de Porto Alegre, para que fizesse uma avaliação médica, a fim de investigar a possível etiologia da síndrome. Após levantamento médico/genético, o laudo confirmou o diagnóstico. Para fins de pesquisa, a responsável pelo paciente assinou o Termo de Consentimento Livre e Esclarecido, antes de iniciar o tratamento.

Neste paciente, observou-se a presença dos três sinais clínicos necessários para a confirmação do diagnóstico da síndrome de Christ-Siemens-Touraine (displasia ectodérmica):

\section{Hipotricose (figura 01);}

2. Hipohidrose (Figura 02);

3. Agenesia de dentes decíduos $(54,53,52,62$, $63,64,75,74,73,72,71,85,84,83,82$ e 81 ) (Figura $03)$.

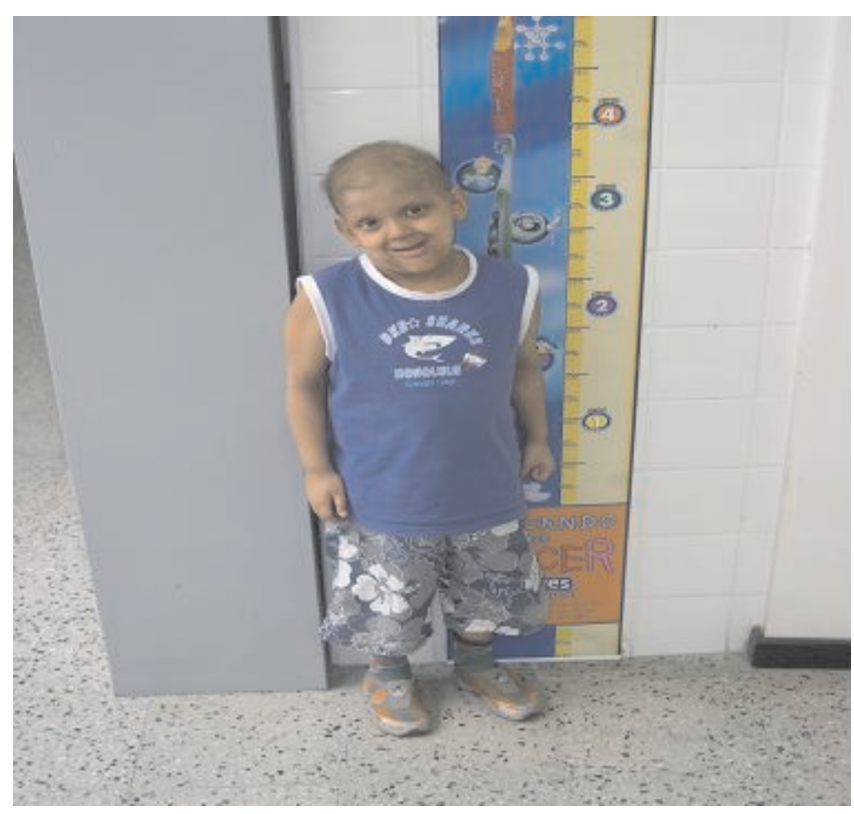

Figura 1 - Primeira visita, paciente com três anos de idade.

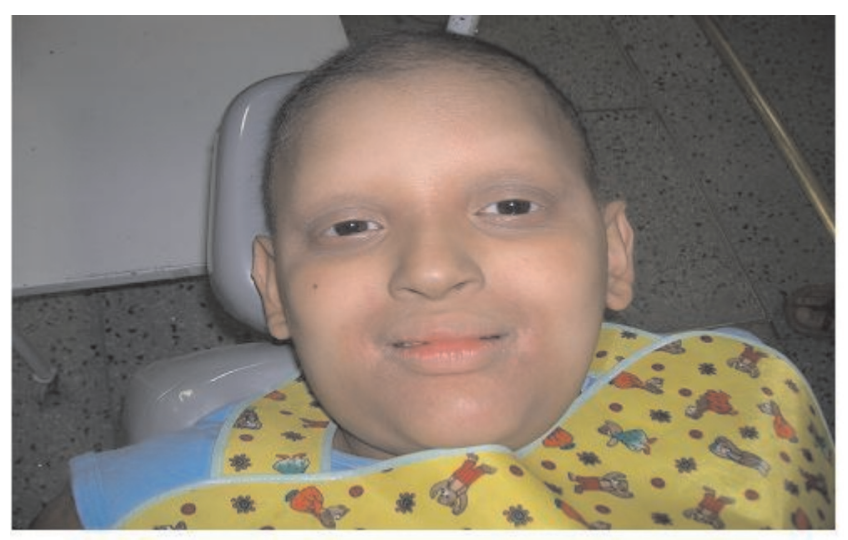

Figura 2 - Sinais de hipotricose e hipohidrose. 


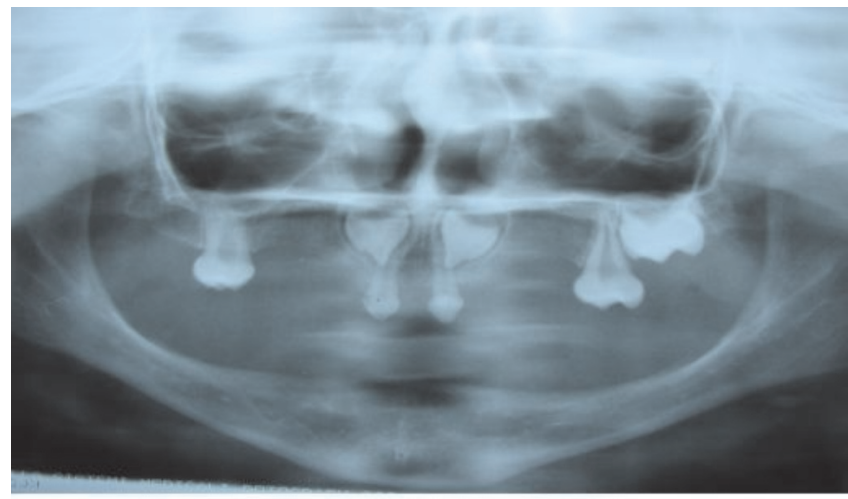

Figura 3 - Ausência de dentes decíduos, presença dos elementos 51, 56, 61 e 66 .

Em uma segunda etapa, foi solicitada documentação ortodôntica completa para um estudo em abordagem multidisciplinar integrando odontopediatria, ortodontia e prótese dentária, elaborando assim, um planejamento reabilitador eficaz que respeitasse o atual momento de desenvolvimento facial da criança.

Para a reabilitação bucal, sob o ponto de vista estético e funcional do paciente, optou-se pela confecção de uma prótese removível superior e uma prótese total inferior, com o intuito de restabelecer a dimensão vertical de oclusão, a mastigação, deglutição e fonação, estética e conforto psico-social. Observou-se, após a instalação das próteses, uma melhora bastante significativa em todos os aspectos anteriormente citados e a satisfação imediata do paciente juntamente com seus familiares (figuras 4,5 e 6 ).

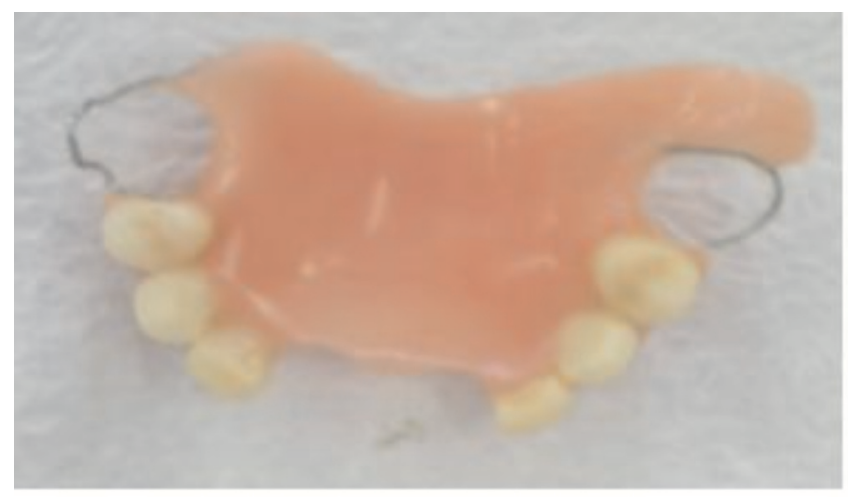

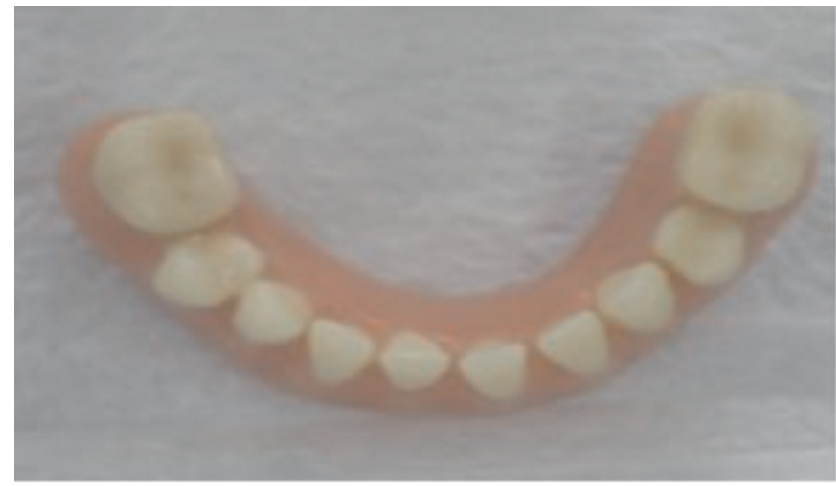

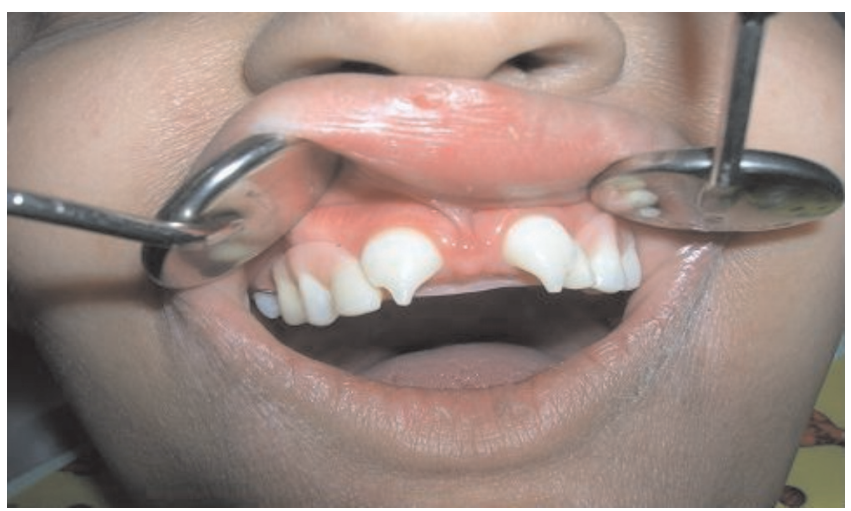

Figuras 4, 5 e 6 - Reabilitação com próteses removíveis (superior/inferior).

Após a instalação das próteses e adaptação das mesmas, o paciente freqüentou mensalmente a Bebê Clínica, para o acompanhamento do seu desenvolvimento facial, condições bucais, condições das próteses, bem como para realizar desgaste compensatório nas mesmas, durante a erupção dos dentes permanentes. Até a última consulta, os únicos dentes permanentes presentes na arcada superior eram os elementos 11, 21,16 e 26 . Como era esperado, nenhum elemento dental formou-se na arcada inferior.

Com a irrupção completa dos dentes permanentes superiores, foram confeccionadas novas próteses removíveis (superior e inferior), já que houve um crescimento ósseo da face do paciente. Os dentes 11 e 21 que, após completa erupção, apresentavam formato conóide, foram submetidos a restaurações adesivas, utilizando resina composta (Z250 - Dentsply), melhorando a estética do sorriso do paciente. (figuras 7, 8 e 9) 


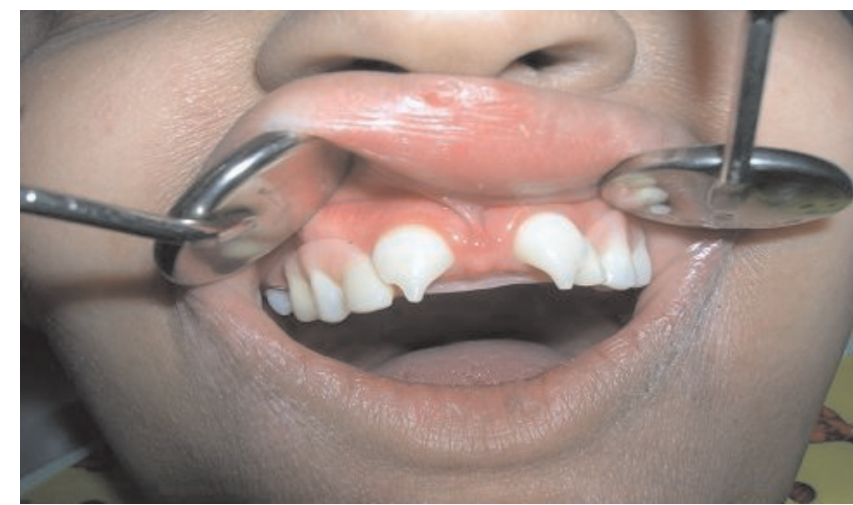

Figura 7 - Dentes permanentes anteriores em formato conóide.

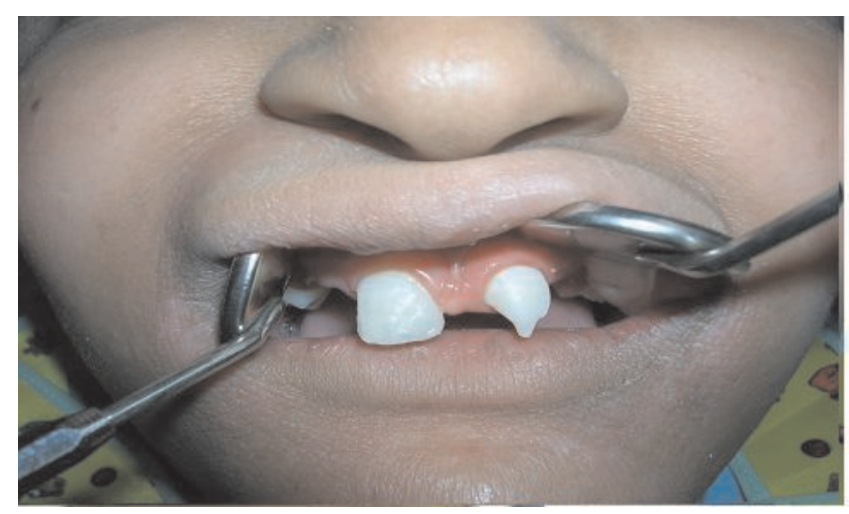

Figura 8 -Restauração dente 11 e 21 com resina composta.

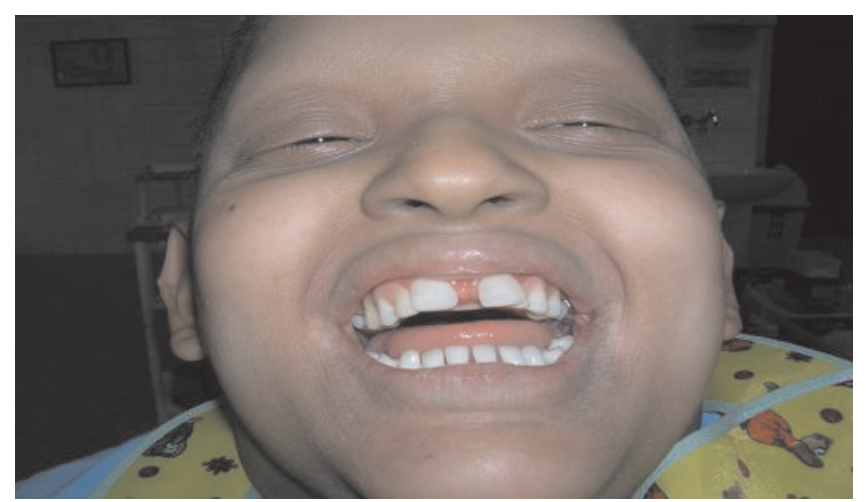

Figura 9 - Paciente com próteses instaladas e dentes anteriores restaurados com resina.

\section{Conclusão}

A avaliação e plano de tratamento odontológico dos portadores da displasia do ectoderma devem estar relacionados diretamente às suas diversas manifes- tações clínicas, a fim de oferecer uma melhor condição bucal ao paciente. No que diz respeito às restaurações estéticas em dentes decíduos ou permanentes em fase de erupção, deve-se manter o paciente em controle periódico, para evitar qualquer alteração no que diz respeito à direção de erupção dos dentes encobertos pelas restaurações. Com a colocação das próteses, pôde-se estabelecer um plano de oclusão, a dimensão vertical, a função dentária, a fonação, a estética e a substituição dos elementos dentários inexistentes, promovendo dessa forma a saúde física e mental do paciente.

No momento atual, o paciente encontra-se em controle trimestral, para avaliação das condições do trabalho protético e das restaurações realizadas. Após crescimento das estruturas da face, o paciente realizará enxerto ósseo e implantes osseointegrados, a fim de substituir as próteses removíveis por overdentures, melhorando ainda mais a sua condição bucal.

\section{REFERÊNCIAS}

1. BARTSTRA, H.L.; HULSMANS, R.F.; STEIJLEN, P.M.; RUIGE, M. de; DIE-SMULDERS, C.E.;CASSIMAN, J.J. Mosaic expression of hipohydrotic ectodermal dysplasia in a isolated affected female child. Arch. Dermatol. 1994; 130: 1421-4.

2. BERGENDAL B. Prosthetic habilitation of a young patient with hypohydrotic ectodermal dysplasia and oligodontia: a case report of 20 years of treatment. Int. J. Prosthodont. 2001; 14:471-9.

3. CORRÊA, M.S.N.P.; ULSON, R.C.B.; RODRIGUES, C.R.; AZEVEDO, A.M. Displasia ectodérmica hereditária: revista da literatura com relato de caso clínico. Rev Paul Odontol, 1997; 19(1):30-4.

4. DANIEL E.; McCURDY E.A.; SHASHI V.; MCGUIRT W.F. Ectodermal dysplasia: otorrinolaryngologis manifestations and management. Laryngoscope. 2002; 112: 962-7.

5. GARDEL P.; MERCIER C.; MOLHANT G. Christ-SiemensTouraine syndrome: a new case. Rev. Stomatol. Cir. Maxillofac. 1984; 85 : 115-8.

6. HERTZ JM.; NORGAARD H.R.; JUNCKER I.; KJELDSEN M.; GREGERSEN N. A novel missence mutation (402c-t) in 1 in the EDA gene in a family with X linked hypohidrotic ectodermal dysplasia. Clin. Genet. 1998; 53: 205-9.

7. KOBIELAKA.; KOBIELAK K.; BIEDZIAK B.; TRZECIAK W.H. A novel mutation A $1270 \mathrm{G}$ of the EDA 1 gene causing TYR343CYS substitution in ectodis plasin-A in a family with 


\section{4}

anhydrotic ectodermal dysplasia. Acta Biochim Polonica. 2003; 255-58.

8. MOTIL K.J.; FETE T.J.; FRALEY J.K.; SCHULTZ R.J.; FOY T.M.; OCHS U.; SYBERT V.P. Growth characteristics of children with ectodermal dysplasia syndromes. Pediatrics. 2005; 116 : 229-234.

9. MUZIOL.L.; BUCCIP.; CARILEF.; RICCITIELLOF.; SCOTTI C.; COCCIAE.; RAPPELLI G. Prosthetic reabilitation of a child affected from anhydrotic ectodermal dysplasia: a case report. The Journal of Contemporany Dental Practice. 2005; 6: 120-6.

10. NOVAIS S.M.A.; ABUD J.M. Síndrome da displasia ecto-

dérmica hereditária - revisão da literatura com relato de caso clínico. Rev Ibero-amer Odontoped Odontol Bebê 2004; 7(37): 243-50.

11. OLIVEIRA E.S.; SAMPAIO E.; MAIA L.C.; VALENÇA A.M.G. Displasia ectodérmica hereditária anidrótica - relato de um caso raro. J Bras Odontoped Odontol Bebê 2000; 3(15): 374-80.

12. TOLEDOA.O. de.; GOMIDEM.B.B.; LEALS.C.; BEZERRA A.C.B.; OTERO S.A.M. Displasia ectodérmica - acompanhamento de caso clínico por dez anos. Rev Ibero-amer Odontoped Odontol Bebê 2006, 9(47): 20-24. 